\title{
PRESENTATION \\ Methodological challenges in participation research
}

\section{PRESENTACIÓN}

Desafíos metodológicos en la investigación de la participación

\author{
JOAN FoNT jfont@iesa.csic.es \\ Instituto de Estudios Sociales Avanzados (IESA) Spain \\ Consejo Superior de Investigaciones Científicas (CSIC) Spain
}

Donatella della PoRTA donatella.dellaporta@eui.ev

European University Institute. Italy

Yves SinTOMER sy@cmb.hu-berlin.de

Institut Universitaire de France. France

CSU-CRESPPA (CNRS/Université de Paris 8)

Participation is a well-established subject in the social sciences. Individual participation, non-governmental organizations, interest groups, and social movements have all been important fields of research for years, at least among sociologists and political scientists. Each of these areas has also developed its own methodological traditions and debates, permitting new researchers entering the field to have a clear idea of the choices offered them if they want to study the identities of participants in social movements or the new forms of online participation.

More recently, a different kind of citizen participation has become more widespread: a participation that is non-conventional because it takes place beyond elections and party politics, but which is also institutional because it is organized or at least sustained by local governments or other public institutions. Citizen participation is not understood here primarily as the act of voting or joining a political organization, nor is it conceived as the involvement in social movements or even NGOs. Instead it consists of the involvement in specific and relatively new kinds of public spheres that enable citizens to be associated with the political and administrative decision-making process. To a certain extent, it goes beyond classical representative government, where rulers and public opinion interact only in very fluid ways. These specific participation mechanisms had existed in the past, but have developed more strongly in the last two or three decades. Participatory and deliberative experiments are in fact now part of the normal political and administrative decision-making arena. New devices have been invented, tested and partly routinized, and new professional careers have been created to nurture them. Clearly, participatory or deliberative democratic institutions are not the whole story in contemporary politics and 
policy, but they are now part of the story. This is why their concrete outcomes need to be analyzed together with the factors that push in this direction, the kind of actors involved, and the techniques and skills that are mobilized.

Empirical analysis in this framework presents some specific challenges, but also some more common ones. Part of the methodological dilemmas researchers in this field face are in fact quite distinct from those in other participation-related areas. For example, they need to use information produced by public institutions quite a bit more often than others and need to discuss their specific sources of bias. However, many of the methodological challenges are quite common and most of the substantive issues to be discussed also concern researchers of the above-mentioned neighboring fields: all of them need to understand why and when people mobilize or how these activities are related or not with public debate and public policies. This is at the root of the idea of putting together a discussion of methodological issues that allowed mixing this new field of research with other researchers dealing with other participatory subjects.

This issue of the Revista Internacional de Sociología aims at offering a rich -although not exhaustive - panorama of the methodologies that researchers use to study these phenomena ${ }^{1}$. The issue focuses mostly on political sociology and political science research (for example, urban studies, history, or science and technology studies are less widely represented or not at all). This issue is one of the outcomes of a conference organized in November 2011 in Cordoba at the IESA-CSIC (Institute for Advanced Social Studies, National Council for Scientific Research)2, and can be viewed as the first attempt to address a topic which had not been collectively tackled before.

From the reading of the articles that have been included, five lessons and questions concerning the way in which participation research develops its methodologies can be learned.

(1) The variety of methods that have been used by scholars who have analyzed participatory processes is very impressive. The articles which are included in this issue range from large $\mathrm{N}$ to small $\mathrm{N}$ quantitative research, from experimental research to surveys and ethnography, from case studies to comparative analysis, from autonomous

\footnotetext{
${ }^{1}$ An exhaustive panorama should have included other contributions on approaches such as the Deliberative Quality Index (Steiner et al., 2004; Steenbergen et al., 2003, the use of quantitative analysis to scrutinize the participants in participatory processes (Fedozzi, 2007), the role of online participation or the comparison of case studies.

${ }^{2}$ Many of these methodological concerns emerged as a result of the development of the MECPALO (Mechanisms of citizen participation in Southern Europe: causes and consequences) project. We acknowledge the financial support from the Ministry of Science and Innovation for the development of this project (CSO 2009-08968) as well as for the organization of the conference. The Regional Government of Andalusia also contributed financially to the conference, which also benefited from the support of the IESA. We also thank Graham Smith, whose concluding comments on the conference have been partially incorporated into this introduction.
} 
activist-research to various other kinds of connections between academics and social or political actors. Some of them make a single exploration of the possibilities and limits of a single methodological approach, but several establish an explicit dialogue between them (Beatriz Mañas or Julien Talpin) or discuss the potentials and limits of their possible combination (Galais and colleagues). Some raise very general epistemological questions (Heloise $\mathrm{Nez}$ ), while still others focus on the dilemmas of variable operationalization (Bengtsson).

A superficial observer could find this confusing. We argue something different: this situation is a clear sign that this field of study has reached its maturity. Research on institutional participation may well not be a central concern of political sociology or political science, but it is now a field which attracts many scholars, and one with journals specifically dedicated to the topic (the Journal of Public Deliberation in English, Participations in French), particular sections in national or international academic conferences, common references beyond the national borders, specific debates and controversies. Yet methodological issues have not been at the forefront, and this is precisely a limitation we would like to overcome in this issue of the Revista Internacional de Sociología.

(2) This issue is a claim against methodological monism and a call for methodological pluralism (Della Porta and Keating 2008). It is a good thing that so many methods are used in research on citizen participation. The simple oppositions such as quantitative vs. qualitative, large vs. small $\mathrm{N}$ studies, case studies vs. comparative surveys are meaningless. This field of study is now sufficiently mature to require its scholars to cross the various methodologies and combine their different approaches in order to enlarge upon and deepen their understanding of this innovative form of participation. While this could appear to be a banal claim, in fact this is unfortunately not often the case.

If we place the articles that follow in a broader context, it is clear that methodologies in participation research are not confined within national borders. However, it is also clear that national or regional traditions exist: action research is quite relevant in the United Kingdom, but it is probably more prevalent in Southern Europe; quantitative and experimental traditions exist everywhere but their hegemony is larger in those countries which belong more closely to the Anglo-Saxon tradition. This means that there is much to gain from transnational encounters, but it also means that if we are moving in the direction of methodological pluralism, we need to increase methodological debates beyond national borders at the European and international levels.

Specific challenges also arise from the large presence of research focusing on case studies, or at most the comparison between two or three case studies. Even if extremely enriching within a logic of discovery which dominates any new field of research, case studies clearly face problems of generalization. Different proposals have been made in order to deal with this question while remaining in the frame of qualitative research: the "grounded theory" (Glaser, Strauss, 1967), the "extended case method" (Burawoy, 1998; Eliasoph, Lichterman, 1999), and "thinking by case" (Ragin, Becker, 1991; Passeron, Revel, 2005). However, many studies are less sophisticated and convincing and the 
numerous edited volumes or journal issues that aim at comparing these case studies most often put together works that have been conducted with different methodologies and concepts. In addition, the issue of articulating qualitative case studies with comparative quantitative studies is generally not addressed.

While one could agree that the time has come to enter a new period and produce broader comparisons relying on the same concepts and methodologies in order to be more reliable and make in-depth comparisons (Sintomer et al., 2011), these present challenges of their own. First, comparative quantitative studies would help to better understand the specificity of each particular process and especially of those "good practices" that are most often the object of case studies and that differ greatly from ordinary or more modest citizen participation devices (Font, Galais, 2011; Baiocchi, Heller, Silva, 2011). Firstly, however, these studies present the need for reliable sources on a large number of cases, which are rarely available. Additionally, quantitative scholars tend to rely mostly on methods derived from social psychology, testing their theoretical hypothesis through experimental laboratory designs that do not consider the impact of social contexts and the huge difference between an experiment that participants see as a game and a real experience that affects them in a much more complex and deeper way (see Julien Talpin in this issue and Dimitrescu and Blais, 2011). For example, many articles uncritically refer to the "polarization thesis", which claims that deliberation tends to polarize the opinions of those who participate (Sunstein, 2000), without mentioning that this effect observed in laboratory experiments is rarely observable in most of the empirical case studies on citizen participation. Also, references to the growing academic production of opinion surveys on participation often lack an epistemic reflection on what "public opinion" is or on the limitations of the data produced (see the contributions of Beatriz Mañas and of Åsa Bengtsson in this issue, and Blondiaux, 1998).

(3) The comparison of methodologies on the research object "citizen participation" also enlightens the way in which social sciences usually work. The positivist view tries to imitate the logic of natural science. In this "Galilean" paradigm, the objective is to establish causal laws, positive incontestable findings, and permanent regularities. This view generally misses the epistemic implications of the probability revolution and especially quantic physics (Hacking, 1990; Gigerenzer et al. 1989). It ignores the results of decades of social studies of science, particularly on the specificity of the complex logic of scientific discovery and its artisanal dimension before the scientific results may be routinized (Latour, Woolgar, 1986; Shapin, Schaffer, 2011). When applied to the research on a contemporary phenomenon such as citizen participation, where experimental routines in laboratories easily become all the more artificial, this "Galilean" paradigm seems particularly problematic. Even more so when research is confronted with the scarcity, the heterogeneity and the limited reliability of data, and the ensuing difficulty of generalizing the findings. This is why most research on citizen participation tends rather to function according to what Carlo Ginzburg (1992) calls the "evidential paradigm": like hunters, detectives and 
psychoanalysts, researchers try to make the best of partial certainties, to interpret existing clues and search for new ones, to put them together, to couple intuition and sequences of controlled tests in order to reconstruct a plausible scenario. A scenario that can hardly produce a positive law, but can nevertheless contribute to our understanding of a quickly developing phenomenon.

As it appears clearly in this issue of the Revista Internacional de Sociología, this is no less true for quantitative research than for qualitative research, or for large $\mathrm{N}$ studies than for small $\mathrm{N}$ studies. In fact, the very existence of different methodologies on the same object, and the contrasted (but also complementary) light they shed on it, is an argument in favor of the "evidential paradigm". The findings produced following one particular method can be considered clues, and the confrontation of these multiple -and often contradictory - clues helps to produce a more robust knowledge, but one could hardly speak of causal laws resulting from these combinations, and even less so when focusing on only one method ${ }^{3}$.

(4) The research field on citizen participation seems particularly interesting to the extent that it "tastes" different from other fields of the social sciences, particularly because many authors implicitly or explicitly have another conception of what objectivity is. Most often, the mainstream social sciences - and this is even truer for political scienceassume that objectivity can be reached through the neutrality of the researcher and his or her detached view of the object. This positivist view of objectivity does not take into account that any particular methodology — and any particular theory - interprets its object according to a particular framing, or to put it more radically, constructs its object at the same time as it analyzes it. In fact, this is not specific to the social sciences and a similar argument has been made in the realm of natural science, particularly concerning quantic physics and nanotechnologies (Daston, Galison, 2010). In addition, researchers are not just observers: they are usually involved in the society they analyze or of which they are members; they share at least part of their episteme. The empirical analysis also largely depends on the decisions of actors other than scientists, who co-determine the structures of research and higher education, the research topics towards which the money flows, and often the methodological instruments used. Globally, the impressive development of the modern sciences has been largely due to their pragmatic orientation and to the collaboration of scientists, higher civil servants, the military, market actors and, less often, citizen movements (Pestre, 2013).

Fundamentally, the activity of social scientists is part of the social construction of the reality (Berger, Luckmann, 1967). What they do is included in a larger social and political debate that takes place in the social and political contexts in which they live. This does not mean that their works lack any specificity and that they cannot be objective.

\footnotetext{
${ }^{3}$ These methodological arguments have something to do with the comprehensive sociology that was proposed by Max Weber (Weber, 2007; Colliot-Thélène, 2001).
} 
It only implies that the objectivity they can achieve has not to be confused with neutrality, detachment, or incontestability. It is something that the German word "Sachlichkeit" expresses well: the objectivity that a social scientist can claim is largely "procedural" and pragmatic. It rests on the coherence of the argumentation, the inclusion of the most significant data, the potential control of the sources by other scholars. Two additional factors also contribute to it. First, having robust and coherent methodologies that explicitly or implicitly address every aspect, from epistemics to operationalization. Second, adopting a reflexive standpoint on each of these aspects and not taking their usefulness for granted also contributes to moving in this direction. This is why it is a problem that critical exchanges on methodology have not been developed sufficiently in participation research, and one of the goals of the present issue of the Revista Internacional de Sociología is precisely to contribute to addressing this problem.

It is interesting that many of the scholars involved in research on citizen participation do not claim to be neutral: they rather recognize their involvement, considering it a powerful incentive and a useful tool for their scientific activity. Most often, they influence, evaluate or even conceive the devices used by social and political actors. More than in other fields of research, they cooperate with citizens' movements and with the public administrations developing these processes. In fact, the very development of this academic field is part of a broader movement of democratic innovations, and participation research is at the same time a result of this development and a factor that favors it. That this practical implication strongly conditions the research being developed in this field is an aspect that deserves attention as lessons can be learnt from the successes and failures of the type of mechanisms that researchers address (e.g. how to develop more effective participatory mechanisms).

As Héloïse Nez shows in her article and as the variety of contributions assembled in this issue testify to, different relations are possible between social scientists and the other actors. Several contributors show sympathy towards the most innovative experiments of participation and regularly discuss with their animators. Some directly work in designing participatory devices (Judith Bakker and Bas Denters), or have conducted the research in an association that does so (Heloïse Nez). Finally, others (Miguel Martínez and Elísabeth Lorenzi) even conceive of their research more from the point of view of the activists than of the professional scholars. Each of these positions (that do not exhaust the full range of possible options) has advantages and poses specific challenges, but they all share the recognition of the involvement of the researcher and a non-positivist view of objectivity. One can say that in this respect they are representative of the state of the art in the field of participation research. This is a relevant position in this field and, as such, these articles contribute to representing here the plurality of positions that researchers in this area have.

(5) Finally, we would like to argue that the dynamic research field on citizen participation is confronted with several additional methodological challenges of which we are going to mention four: 
(i) Research about participation has devoted most of its efforts to understanding the motives, demographics, biographies or identities of participants. However, a full understanding of why participation is so unequally distributed can only be achieved if we also try to know something about those who do not participate. This same logic can be applied to the new field of institutional participation. How can we combine research on participatory process with research on cases with no participation? Are the methods used in participation research sufficient to grasp the limited extension of participatory democracy? For example, what methods should be used in order to better understand those politicians or civil servants that do not launch participatory processes, or those citizens that do not participate? Observation is much more difficult here, and in-depth interviews may be less relevant than with participants, especially when scarce resources are available for research. Could large $\mathrm{N}$ quantitative surveys really be sufficient to fill the gap? In any case, this is only one example that shows that initiating a dialogue with neighboring fields, from social movement research to organizational or public policy analysis, which have also addressed similar challenges, is crucial if we need to make progress using the experience of areas that have a longer history.

(ii) What is the role that historical methods can play in this endeavor? Until now, most of the research on citizen participation has been carried out on contemporary processes. However, even if participatory mechanisms have become more common, they had also been important in the past in some polities (from Athens to Switzerland or small assembly-led communities). In fact, it seems fundamental to take these past examples into account when analyzing the present as much of the logic of these mechanisms is difficult to understand without an effort to know about their origins and the contexts in which they developed. Some historians have worked on participatory or deliberative experiments, but generally without making the link with the questions and findings of scholars who work on the contemporary. Methodologically, it is clearly challenging to combine the results of research on present experiments (using methods that range from opinion polls to ethnography) with those on past examples, which is based on (often scant) available archival materials.

(iii) How can participation research better compare many cases and generalize its findings? At the point of maturity of this field of study, it seems necessary (as we argued earlier on) to go beyond single case studies and work on systematic comparisons and a broader synthesis. However, practices on comparative research are much less developed in this field than they are in history or in anthropology, and we do not have anything comparable to the reflection on connected" or "crossed histories" (Subrahmanyam, 1997; Werner, Zimmermann, 2004). In addition, comparative broad-scale research requires a sum of money and energy that is rarely available for research on this topic. Small $\mathrm{N}$ research helps to better understand the relations between several cases, but only if previous case studies are not only reliable, but also (methodologically) coherent with each other. Large $\mathrm{N}$ research design such as surveys on actual participation processes 
broadens the panorama but has to rely on scarce and often distorted data - and therefore needs to be articulated with qualitative case studies in order to deepen its analysis. Experimentally based research can hardly generalize its findings without testing them outdoors. And very often, scholars are deeply divided concerning the value of such and such a methodology and are reluctant to collaborate with others that do not share their methodological views. Approaches like the one used in the article by Ryan and Smith are an interesting avenue to be explored, even if they may not be applied to every research question.

(v) How do we cross the methods without falling into inconsistent results? In this issue, Carolina Galais and her co-authors show that it is not so simple to combine various quantitative methods, such as web mining and data survey, which seem to be not so far away from each other if compared with qualitative methods. But can a broader synthesis of quantitative and qualitative research findings be made without a deep epistemological reflection on the implications of each method? Even if, as della Porta and Keating (2008) argue, epistemology and the choice of methods do not easily align (quantitative analysis could be produced by less than positivist scholars, and ethnography could be instead conceived in positivist terms), a triangulation of different methods can still be problematic. For example, how could the ethnographic research conducted in the style proposed by Julien Talpin in his article really be articulated with the work of experimentally based research? Can the criticisms raised by Talpin be considered a call for caution methodological pluralism and the triangulation of techniques or does it point to the idea that the starting ground on which each of these traditions is built is so different that this combination is hardly plausible?

This Revista Internacional de Sociología issue does not answer all these questions, but it at least tries to underline their importance and makes a call to address them more systematically.

\section{REFERENCES}

Baiocchi, G., Heller, P. and M. Silva. 2011. Bootstrapping Democracy. Transforming Local Governance and Civil Society in Brazil. Stanford: Stanford University Press.

Berger,P and T. Luckmann. 1967. The Social Construction of Reality: A Treatise in the Sociology of Knowledge, New York: Anchor.

Blondiaux L, 1998. La fabrique de l'opinion. Une histoire sociale des sondages. Paris: Seuil.

Burawoy, M. 1998. "The Extended Case Method." Sociological Theory 16(1):4-33.

Colliot-Thélène, C. 2001. Etudes wébériennes. Paris: PUF.

Daston, PL and P. Galison. 2010. Objectivity. New York: Zone Books. 
Della Porta, D and M. Keating (eds.) 2008. Approaches and Methodologies in the Social Sciences: A Pluralist Perspective. Cambridge: Cambridge University Press.

Dumitrescu, D and A. Blais. 2011. "Increased Realism at Lower Cost: The Case for the Hybrid Experiment." PS: Political Science \& Politics 44:521-523.

Eliasoph, N and P. Lichterman. 1999, "We Begin with Our Favorite Theory: Reconstructing the Extended Case Method." Sociological Theory 17(2):228-234.

Fedozzi, L. 2007. Observando o Orçamento Partecipativo de Porto Alegre. Porto Alegre: Tomo.

Font, J. and C. Galais. 2011. "The qualities of local participation: The explanatory role of ideology, external support and civil society as organizer." International Journal of Urban and Regional Research 35(5):932-48.

Gigerenzer G. et alii. 1989. The Empire of Chance. How Probability Changed Science and Everyday Life. Cambridge: Cambridge University Press.

Carlo G., 1992. Clues, Myths, and the Historical Method. Baltimore: The Johns Hopkins University Press.

Glaser, B and A. Strauss. 1967. The Discovery of Grounded Theory. New York: Aldine de Gruyter.

Hacking I. 1999. The Taming of Chance. Cambridge: Cambridge University Press.

Latour, B. and S. Woolgar. 1986. Laboratory Life: The Construction of Scientific Facts. Princeton: Princeton University Press.

Passeron, J.C. and J. Revel [ed.] 2005. Penser par cas. Paris: EHESS.

Pestre D. 2013. A contre-science, politique et savoirs des sociétés contemporaines. Paris: Seuil.

Ragin, Ch. and H. Becker eds. 1992. What Is a Case? Exploring the Foundations of Social Inquiry. Cambridge: Cambridge University Press.

Steenbergen, M. Bächtiger, A., Spörndli, M. and J. Steiner. 2003. "Measuring Political Deliberation, A Discourse Quality Index." Comparative European Politics 1(1):21-48.

Steiner J. et alii. 2004. Deliberative Democracy in Action. Cambridge: Cambridge University Press.

Subrahmanyam, S. 1997. "Connected Histories - Notes towards a Reconfiguration of Early Modern Eurasia." Modern Asian Studies July 31:3.

Sunstein C. 2000. "Deliberative Trouble? Why Groups Go to Extremes." The Yale Law Journal 110(1):71-111.

Sintomer, Y., Ganuza, E., Herzberg, C and A. Röcke. 2011. Democracia participativa y modernización de los servicios públicos: Investigación sobre las experiencias de presupuesto participativo en Europa. La Découverte (Paris)/TNI (Amsterdam).

Shapin, S. and S. Schaffer. 2011. Leviathan and the Air-Pump: Hobbes, Boyle, and the Experimental Life. Princeton: Princeton University Press.

Weber, M. 2007. Essays in Sociology. London: Routledge.

Werner, M. and B. Zimmermann [ed.] 2004. De la comparaison à l'histoire croisée. Le Seuil: Paris. 
JOAN FONT is a senior researcher at the IESA/CSIC working on citizen participation in public policies. He was the research director at the major public survey institution (CIS) in 2004-2008. He has been a senior lecturer at the Political Science department of UAB (Barcelona) and a visiting scholar at the EUI (Florence) and UCD (Dublin).

Donatella della Porta is professor of sociology in the Department of Political and Social Sciences at the European University Institute. Among her recent publications are: Meeting democracy (Cambridge university press, 2013); Clandestine Political violence (Cambridge University press 2013), Can democracy be Saved (Polity 2013), Mobilizing on the Extreme Right (Oxford University Press 2012); Social Movements and Europeanization, Oxford University Press, 2009; (ed.) Another Europe, Routledge, 2009; (ed.) Democracy in Social Movements, Palgrave, 2009; Approaches and Methodologies in the Social Sciences (with Michael Keating), Cambridge University Press; (with Gianni Piazza), Voices from the Valley; Voices from the Streat Berghan, 2008; The Global Justice Movement, Paradigm, 2007.

Yves Sintomer is professor of political science at Paris 8 University, Senior fellow at the Institut Universitaire de France, and associate researcher at Neuchâtel University and Marc Bloch Centre (Humboldt University Berlin/CNRS). He received a PhD of political and social sciences (European University Institute, Florence) and has a Habilitation to direct research (Paris 5 University). He has studied and taught in Harvard, Frankfurt/Main, Complutense-Madrid, Lausanne (Switzerland), UCL (Belgian), Universidad del Pais Vasco, Catania (Italy). He has been deputy-director of the Marc Bloch Center (Berlin). Last publication (2011): Petite histoire de l'expérimentation démocratique. Tirage au sort et politique d'Athènes à nos jours. París: La Découverte.

RECEIVED: 12 November 2012

ACCEPTED: 26 November 2012 